\title{
Posterior cranial fossa venous extradural haematoma: an uncommon form of intracranial injury
}

H A Khwaja, P J Hormbrey

\begin{abstract}
Extradural haematomas are commonly associated with direct trauma to the temporal bones of the cranium resulting in damage to the middle meningeal artery or its branches. A case is presented of an occipital skull fracture with venous sinus bleeding that resulted in a posterior cranial fossa extradural haematoma. Bleeding in this area, if unrecognised, may lead rapidly to respiratory arrest secondary to brainstem compression. The presence of significant trauma to the occiput should alert the attending clinician to the possibility of this uncommon but potentially fatal condition.

(Emerg Med f 2001;18:496-497)
\end{abstract}

Keywords: extradural haematoma

Posterior cranial fossa extradural haematomas account for $0.3 \%$ of all head injuries and $10 \%$ of all extradural bleeds. ${ }^{1}$ The majority of extradurals result from fracture of the temporal bone resulting in bleeding from the middle meningeal artery or its branches. However, posterior fossa bleeds associated with occipital trauma are more commonly secondary to dural venous sinus bleeding. ${ }^{2}$

We report a case of an acute posterior fossa venous extradural bleed in a 27 year old man. The case illustrates the importance of early diagnosis of this rare condition and the necessity of swift referral to a neurosurgical unit for definitive treatment.

\section{Case report}

A 27 year old man was transferred from a local community hospital to the John Radcliffe Hospital for further assessment after a head injury. A history had been obtained at the community hospital from the patients' girlfriend that at 0010 am on 8 May 1999 she found him at home on the floor, smelling heavily of alcohol but fully conscious. She also noted he was bleeding from a scalp wound so took him to the local community hospital. $\mathrm{He}$ was assessed there at 0035 am where a $5 \mathrm{~cm}$ occipital scalp laceration was noted and sutured. At $0120 \mathrm{am}$, while still at the hospital, the patient became increasingly drowsy, vomited twice and blood was noted to be trickling from his nostrils. This prompted immediate transfer to the John Radcliffe Hospital for further treatment.

On initial assessment at the John Radcliffe at 0220 am the patient was immediately resuscitated. His airway was clear with no evidence of stridor or wheeze. The patient was however very agitated. Saturations on air were noted to be $93 \%$ and his respiratory rate was 26 breaths/minute so high flow oxygen was administered via a reservoir bag. Chest examination was unremarkable with no clinical evidence of a pneumothorax. Pulse was 60/ minute and blood pressure was $98 / 67 \mathrm{~mm} \mathrm{Hg}$. His blood glucose level was $13.3 \mathrm{mmol} / \mathrm{l}$ and temperature was $34.6^{\circ} \mathrm{C}$. An infusion of warmed Hartmann's solution was started and routine blood tests taken. His GCS was $6 / 15$ $(4 / 6+1 / 5+1 / 4)$ and both pupils reacted sluggishly to light. Scalp examination revealed a $3 \times$ $3 \mathrm{~cm}$ right occipital haematoma with an overlying $5 \mathrm{~cm}$ sutured laceration. Bloodstains were evident from both nostrils and on otoscopy a left haemotympanum was noted. Neck, chest, abdominal, pelvic and peripheral nervous system examinations were unremarkable.

Cervical spine and chest radiographs were normal. While awaiting for anaesthetic review, a set of arterial blood gases on air were done and revealed: $\mathrm{pH} 7.29, \mathrm{P}_{\mathrm{a}} \mathrm{O}_{2} 8.00 \mathrm{KPa}, \mathrm{P}_{\mathrm{a}} \mathrm{CO}_{2}$ $5.5 \mathrm{KPa}, \mathrm{HCO}_{3}^{-} 20.3 \mathrm{mmol} / 1$, Sats $87 \%$. These results were consistent with possible aspiration of vomitus due to the patients' head injury and impaired conscious level. The patient was intubated and computed tomography of his head and neck was done at 0409 am. Computed tomography showed a right occipital skull fracture with an extradural posterior cranial fossa

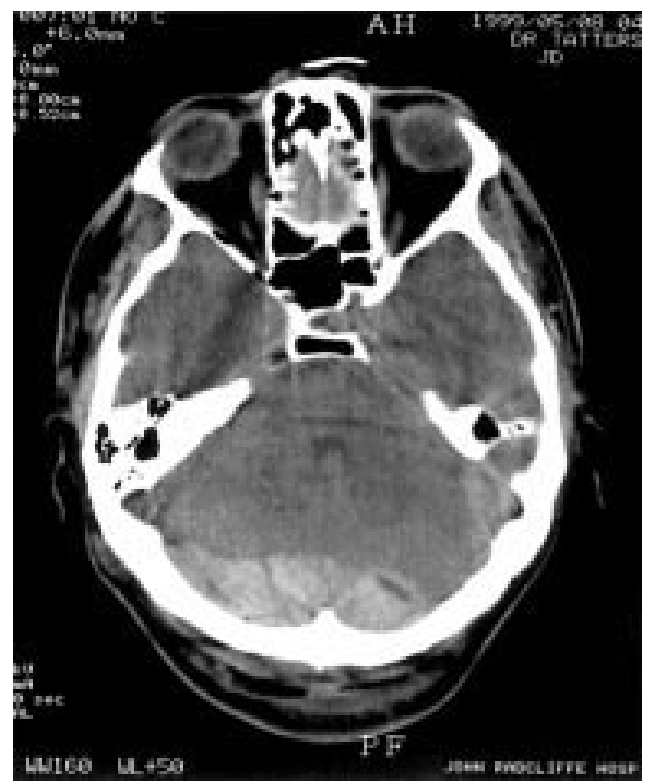

Figure 1 Computed tomography of the brain showing a large posterior cranial fossa extradural haematoma with obvious subcutaneous haematoma overlying the occipital bone. 
haematoma (fig 1). There was also evidence of cerebellar tonsillar descent and early hydrocephalus. Neck computed tomography was normal.

After consultation with the duty neurosurgical team the patient was transferred urgently to the neurosurgical unit at the Radcliffe Infirmary. He underwent a posterior fossa craniectomy and evacuation of the haematoma. Intraoperative findings showed a linear occipital skull fracture to the right of the midline extending across the right transverse venous sinus with surrounding bleeding. Postoperatively the patient spent two days in intensive care. Subsequently, he has made a good recovery but has incurred a mild bilateral sensorineural hearing deficit as a result of the head injury.

\section{Discussion}

This case illustrates how an extradural haematoma may arise within the posterior cranial fossa from a venous sinus tear. Extradural haematomas represent $25 \%-35 \%$ of all traumatic space occupying lesions of the posterior cranial fossa. ${ }^{3}$

Extradural haematoma are classically considered to arise from a blow to the thin temporal bones of the cranium. Underlying these bones lie the middle meningeal artery closely applied to the meningeal layer of dura mater. Trauma to this region damages the artery leading to the commonly recognised form of extradural haematoma. A classification of extradural haematoma based on the interval between the traumatic event and operation is well recognised. They may be acute onset (that is, less than 24 hours), subacute (between 24 hours to 10 days) and chronic (that is, after 10 days). ${ }^{4}$

Posterior fossa extradural haematomas are much less common compared with supratentorial bleeds. They represent about $10 \%$ (range $3.4 \%-12.9 \%$ ) of all cases of extradural haematoma. ${ }^{56}$ These bleeds are commonest in the 20-47 year age group as well as the paediatric age group. ${ }^{7}$ The bleeds are usually associated with an occipital skull fracture. Such a fracture has been demonstrated radiographically in $86 \%$ of cases of proven extradurals though such bleeds may develop despite no demonstrable fracture. ${ }^{8}$ Fisher et al has demonstrated that a posterior cranial fossa fracture in the presence of occipital trauma is of paramount significance. In such patients serious complications develop in $33 \%$ of patients compared with $7 \%$ of those without a fracture. ${ }^{9}$

Brain computed tomography remains the current first line investigation to demonstrate such bleeds. The characteristic image is a well localised, hyperdense, extracerebral biconvex lesion of blood. Zucarello et al have reported that the incidence of additional intracranial lesions in patients with posterior fossa extradural haematoma may be as high as $87.5 \%{ }^{6}$ These include brain contusions and frontal/ temporal intracerebral haematomas secondary to a contracoup mechanism.

The natural history of a posterior fossa extradural haematoma is somewhat variable. In a report of seven cases by Garza-Mercado, three of the patients suffered immediate transient unconsciousness and three patients though neurologically and physiologically stable for the first few hours while in hospital then suffered sudden respiratory arrests. ${ }^{2}$

The relevance of the origin of the bleeding of an extradural haematoma with the clinical picture is still not fully understood. GarzaMercado also found that in five of the seven posterior fossa extradural cases investigated the bleeding was venous in origin. ${ }^{2}$ Thus venous sinus bleeding may explain the chronicity of some extradural bleeds. However, as in our case an acute course of an extradural bleed may result from venous sinus bleeding. Indeed in our patient the time interval from the head injury to the symptoms of vomiting and decreasing GCS was about 70 minutes.

Acute posterior fossa extradural haematomas have been associated with a mortality ranging between $12.5 \%-70 \%{ }^{6}$ The most significant factors influencing mortality include-failure to diagnose the condition early, level of consciousness at time of neurosurgical intervention and existence of associated brain stem lesions. Indeed, early diagnosis is essential as respiratory arrest secondary to cerebellar tonsillar herniation commonly occurs. Consequently emergency medical staff should maintain a high clinical suspicion for the possibility of a posterior fossa extradural haematoma in any patients with head injuries.

Funding: none.

Conflicts of interest: none.

1 Boiten J. Epidural haematoma of the posterior fossa: good results after prompt diagnosis with CT. F Neurol Neurosurg Psychiatry 1989;52:914-15.

2 Garza-Mercado R. Extradural haematoma of the posterior cranial fossa. F Neurosurg 1983;59:664-72.

3 Ammirati M, Tomita T. Posterior fossa epidural haematomas during childhood. Neurosurgery 1984;14:541-4.

4 Meredith JM. Extradural haemorrhage in posterior fossa. Diagnosis and treatment with a report of two surgically Diagnosis and treatment with a report of two
treated patients. Am $\mathcal{F}$ Surg 1961;102:524-31.

5 Borzone M, Altomonte M, Rivano C. Posterior fossa extraBorzone M, Altomonte M, Rivano C. Posterior foss
dural haematomas. F Neurosurg Sci 1991;35:260-1.

6 Zucharello M, Pardatscher K, Andrioli GC, et al. Epidural haematomas of the posterior cranial fossa. Neurosurgery 1981;8:434-47.

7 Gelabert M, Prieto A, Allut AG. Acute bilateral extradural haematoma of posterior cranial fossa. Br $\mathcal{F}$ Neurosurg 1997; 11:573-5.

8 Koc RK, Pasaoglu A, Menku A, et al. Extradural haematomas of the posterior cranial fossa. Neurosurg Rev 1998;21: $52-7$.

9 Fisher RG, Kim JK, Sachs E. Complications in posterior fossa due to occipital trauma-their operability. $\Im A M A$ 1958;167:176-82. 